\title{
Design and Simulation of a New Model for Treatment by NCT
}

\author{
Seyed Alireza Mousavi Shirazi ${ }^{1}$ and Dariush Sardari² \\ ${ }^{1}$ Department of Physics, Sciences College, Islamic Azad University, South Tehran Branch, Tehran 1581819411, Iran \\ ${ }^{2}$ Department of Nuclear Engineering, Technical College, Islamic Azad University, Science and Research Branch, Tehran, Iran
}

Correspondence should be addressed to Seyed Alireza Mousavi Shirazi, a_moosavi@azad.ac.ir

Received 10 July 2012; Revised 24 July 2012; Accepted 31 July 2012

Academic Editor: Xing Chen

Copyright (C) 2012 S. A. Mousavi Shirazi and D. Sardari. This is an open access article distributed under the Creative Commons Attribution License, which permits unrestricted use, distribution, and reproduction in any medium, provided the original work is properly cited.

In this investigation, neutron capture therapy (NCT) through high energy neutrons using Monte Carlo method has been studied. In this study a new method of NCT for a sample liver phantom has been defined, and interaction of $12 \mathrm{MeV}$ neutrons with a multilayer spherical phantom is considered. In order to reach the desirable energy range of neutrons in accord with required energy in absence of eligible clinical neutron source for NCT, this model of phantom might be utilized. The neutron flux and the deposited dose in the all components and different layers of the mentioned phantom are computed by Monte Carlo simulation. The results of Monte Carlo method are compared with analytical method results so that by using a computer program in Turbo-Pascal programming, the deposited dose in the liver phantom has been computed.

\section{Introduction}

Neutron capture therapy (NCT) has been one of the most important methods for treatment of cancers in recent years. This method of radiation therapy is applicable in treatment of liver cancer. During clinical practice, it is always essential to stop absorption of additional dose by normal tissue. On the other hand, measurement and assessment of the absorbed dose and its calibration is an important matter $[1,2]$. Thus computation and modeling of the deposited dose by Monte Carlo method before practical treatment is recommended. An appropriate software tool for this purpose is MCNP4C code. It is a particular engineering solution when BNCT facilities such as low energy neutron source are not available.

In this paper for simulation by MCNP4C code, a phantom is considered so that it has been encased by polyethylene sphere with $20 \mathrm{~cm}$ radius. This sphere is covered with a layer of cadmium which has $100 \mu \mathrm{m}$ thickness $[3,4]$. The cadmium layer has high absorption cross-section for thermal neutrons and helps to reentrance the scattered neutrons from surface of the sphere to the phantom [5]. The polyethylene sphere is surrounded by a graphite shell which has $25 \mathrm{~cm}$ radius and $5 \mathrm{~mm}$ thickness (according to moderation ratio:
$\left.\xi\left(\Sigma_{s} / \Sigma_{a}\right)\right)$. This layer serves as a reflector to reduce escaping the fast neutrons [6].

In the present work, neutrons are emitted from an external source, and after passing through polyethylene and slowing down, their deposited energy in the phantom's materials is computed by the MCNP4C code. The F6 tally in the MCNP4C code is applied. The absorbed energy in the liver is computed through analytical computations as well. It includes generation of random numbers along with using the neutron diffusion equation [7]. The outcomes of two methods are finally compared.

The results of computation provide assurance that whether the absorbed dose in cancerous and healthy tissues is in accord with requirements $[8,9]$. Then neutron therapy would be implemented on the patient. In neutron capture therapy it is suggested to use monoenergetic neutrons. For this purpose, one choice is $\mathrm{D}$-Be source which produces $14 \mathrm{MeV}$ neutrons [10].

As Am-Be source produces a wide spectrum of neutron energies, thus, is not suitable for this purpose [11]. Liver tissue includes substances such as water, glycogen, and heavy molecules like protein. Figure 1 shows interaction of incident neutron and depositing the energy during neutron irradiation. 
TABLE 1: The components and the structural materials of a liver tissue (relating to male sex).

\begin{tabular}{lc}
\hline Mass percent & Material \\
\hline $69.69 \%$ & Water \\
$0.35 \%$ & Glycogen $\left(\mathrm{C}_{24} \mathrm{H}_{42} \mathrm{O}_{21}\right)$ \\
$29.9 \%$ & Protein and Glucose \\
& $\left(\mathrm{C}_{44189} \mathrm{H}_{71252} \mathrm{~N}_{12428} \mathrm{O}_{14007} \mathrm{~S}_{321}\right.$ and $\left.\mathrm{C}_{6} \mathrm{H}_{12} \mathrm{O}_{6}\right)$ \\
\hline
\end{tabular}

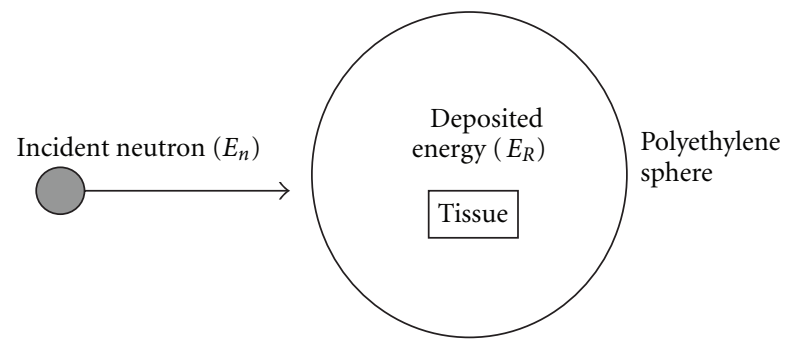

FIgure 1: The emitted neutron from source and entering into sphere including tissue.

\section{Monte Carlo Calculations}

To simulate neutron therapy and related dosimetry, a phantom is considered as shown in Figure 2.

Figure 3 depicts the geometry which has been defined by MCNP4C code, and Figure 4 is a schematic view of the physical shape of the phantom.

Laboratory experiments have already rendered the precise molecular composition of liver tissue according to Table 1 [12].

The composition and geometrical data belonging to liver tissue have been given to MCNP4C as input data $[13,14]$. In the simulation, neutron slowing down has been taken into account as well [15]. The input data to MCNP4C code are the radius of polyethylene sphere $(20 \mathrm{~cm})$, the thickness of cadmium layer $(100 \mu \mathrm{m})$, radius and thickness of graphite reflector $(25 \mathrm{~cm}$ and $5 \mathrm{~mm}$, resp.), and the weight of liver tissue that is $190 \mathrm{~g}$.

\section{Analytical Calculations}

It is essential to obtain data on neutron scattering crosssection and its angular distribution because of computing the neutron penetration in liver tissue (or in the corresponding equivalent material) and obtaining the absorbed energy in it. Since neutrons pass through the polyethylene sphere, the knowledge about neutron angular distribution after scattering is vital. Thus, using the random sampling techniques might help to compute the probability of those neutrons which might be scattered in a definite angle [16]. Since it might be comprehended, the atomic composition of the soft tissue is approximated as well with hydrocarbon materials.

In the process of neutron transport in matter, it is subjected to three major kinds of interactions with carbon and hydrogen nuclei. These are elastic scattering, inelastic scattering, and radioactive capture. Each kind of interactions takes place with a specific probability with a magnitude proportional to related interaction cross-section according to following equations (1)-(4):

$$
\begin{aligned}
& P_{1}=\frac{\sum_{H \text { (Elastic) }}}{\sum_{\text {tot }}}, \\
& P_{2}=\frac{\sum_{C \text { (Elastic) }}}{\sum_{\text {tot }}} .
\end{aligned}
$$

The probability of inelastic scattering in carbon (for the first excitation level in: $4.43 \mathrm{MeV}$ ):

$$
P_{3}=\frac{\sum_{C}}{\sum_{\text {tot }}} .
$$

The probability of inelastic scattering in carbon (for the second excitation level in: $7.65 \mathrm{MeV}$ ):

$$
P_{4}=\frac{\sum_{C}}{\sum_{\text {tot }}} .
$$

The probability of neutron absorption in hydrogen and carbon:

$$
P_{5}=\frac{\left[\sum_{C}+\sum_{H(\text { absorption })}\right]}{\sum_{\text {tot }}} .
$$

Collision of neutrons on carbon and hydrogen nuclei is caused to transfer some energy from neutrons to the target nucleus. The recoiled nucleus moves a short distance through the matter and deposits energy along its path. The problem is to compute the energy of recoiled nucleus. By using the Monte Carlo method, collision history of each neutron might be tracked down to the energy where it is either absorbed or escapes from the volume of material.

The lost energy of neutron in each elastic scattering is described by (5):

$$
E_{1}-E_{2}(\cos \theta) P(\cos \theta) d(\cos \theta) .
$$

$E_{2}$ is also obtained by the following equation (6):

$$
E_{2}=E_{1} \cdot \frac{A^{2}+2 A \cos \theta+1}{(A+1)^{2}} .
$$

Thus the average energy of recoiled nucleus through assuming the isotropic scattering is

$$
\overline{E_{R}}=\frac{2 A E_{1}}{(A+1)^{2}} .
$$

The inelastic scattering of neutron in polyethylene is important. There are two excited statuses in carbon nucleus, namely, $4.43 \mathrm{MeV}$ and $7.65 \mathrm{MeV}$. Thus remarkable value of energy is absorbed in the recoiled nucleus, and $E_{R}$ is less than the energy of inelastic scattered neutrons [17].

The transferred energy to a recoiled nucleus with mass number $A$ due to collision of a neutron with energy $E_{n}$ is computed with (8) [18]:

$$
E_{R}=\frac{2 A}{(A+1)^{2}} E_{n} \cos ^{2} \psi .
$$




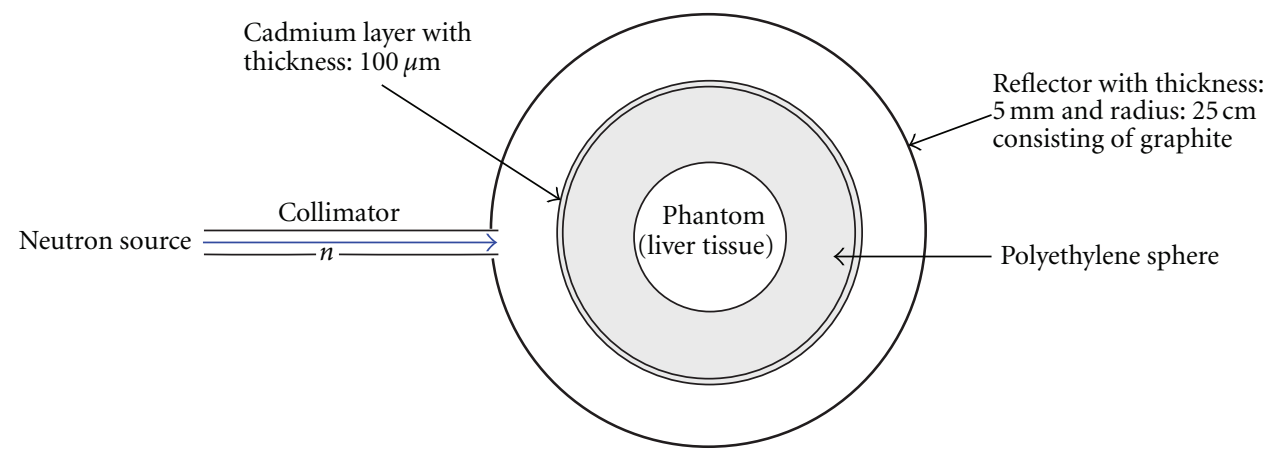

FIgURE 2: The sphere including the liver tissue for the neutron capture therapy.

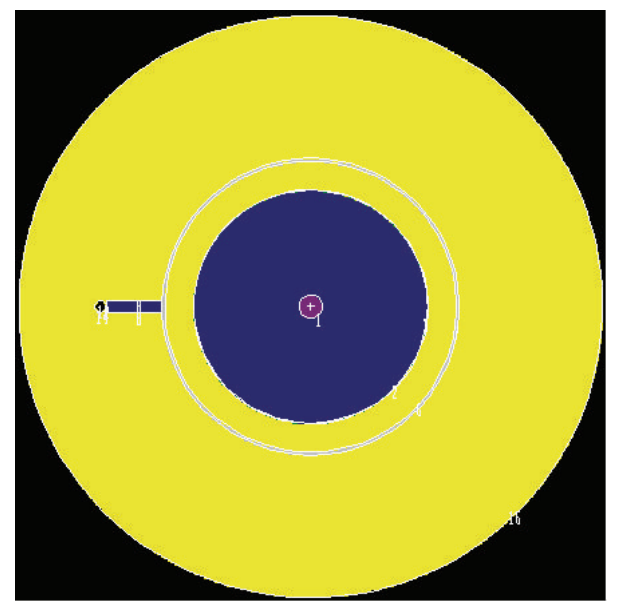

Figure 3: The geometry of the phantom defined by MCNP4C code.

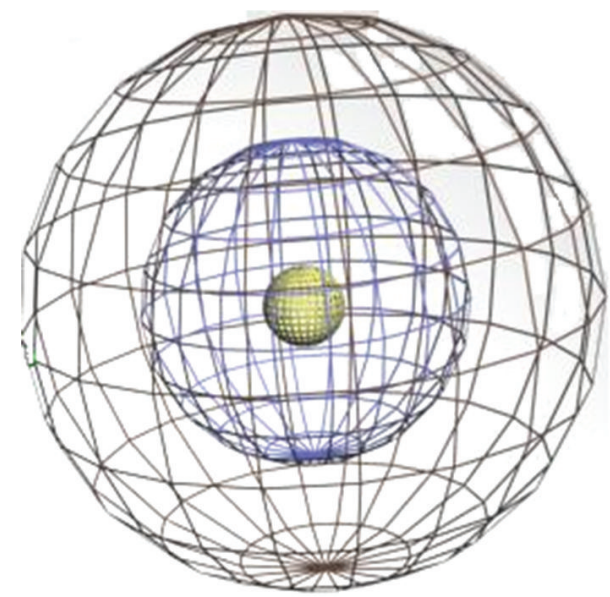

FIGURE 4: The schematic view (3D) of the related geometry.

Since remarkable percentage of the soft tissue is hydrogen, the interaction of neutron with hydrogen must be studied as well. Approximately 85\%-95\% of neutron energy transferred to soft tissue is attributed to its interaction with hydrogen [19]. For instance, for $E_{n}>8 \mathrm{MeV}$ the $(\alpha, n)$ reaction makes the significant fraction of absorbed dose in the tissue.
At $14 \mathrm{MeV}$ the contribution of recoiled proton (hydrogen nucleus) is related to energy deposition phenomenon, that is, $66 \%$ of total, and the rest is due to $\alpha$ particle plus other heavy nuclei $[20,21]$.

In fact, the penetration of neutron through polyethylene sphere and its interaction in liver tissue require precise knowledge about interaction cross-sections and angular distribution of the scattered neutron.

For this purpose by using the Turbo-Pascal programming and considering several values for $E_{n}$ in the interval $0.001-12 \mathrm{MeV}$ and providing the mass number $(A)$ of the components of the phantom as the input to the program, the absorbed dose in the liver tissue $\left(E_{R}\right)$ and other components such as polyethylene sphere, air, and collimator are computed $[\mathrm{Gy}]$. The number of neutron collisions is calculated according to (9):

$$
n=\frac{\ln \left(E_{n} / E_{R}\right)}{\xi}
$$

In order to determine absorbed dose in the phantom or other components such as polyethylene, the numeric range of $E_{n}$ (energy of incident neutrons) and $E_{R}$ (deposited energy) into the number of neutron collisions $(n)$ is divided, and then its value is added to early energy (10):

$$
E_{R(\text { new })}=E_{R}+\frac{E_{n}-E_{R}}{n} .
$$

The Turbo-Pascal programming which has been developed in the present work computes the energy transferred from incident neutrons to the tissue based on given neutron energy, scattering angle $(\psi)$, and mass number of the target nuclei.

Figure 5 shows a schematic view of the phantom which is comprised by four layers. A hypothetical track and slowing down of neutron in consecutive collisions are shown as well. 


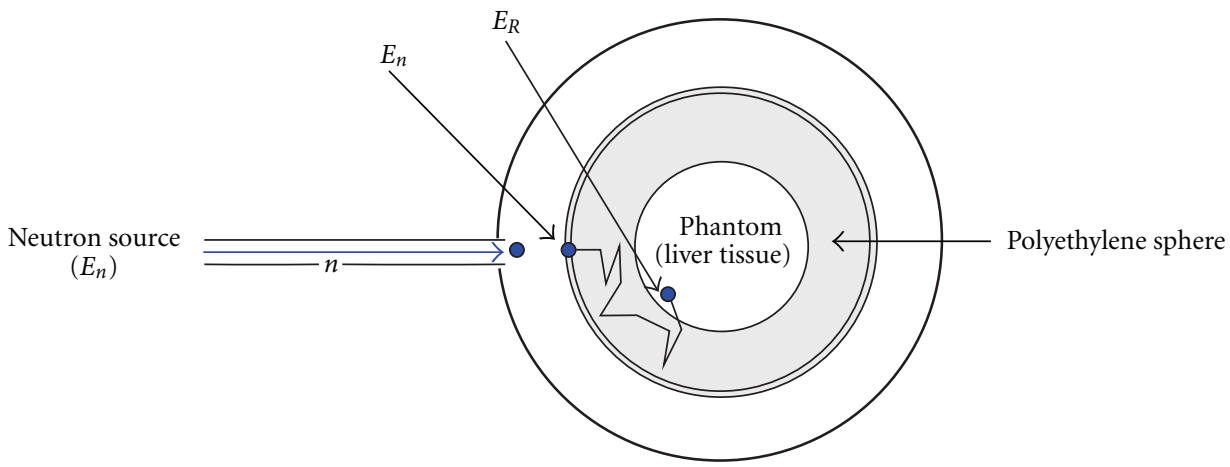

FIGURE 5: The collision of emitted neutron from the external source to the polyethylene shell.

Some useful equations in analyzing the energy transfer of neutron from high energy to the medium are according to (11)-(12) [22]:

$$
\begin{gathered}
E_{R}=E_{n} e^{-n \xi}, \\
L_{\mathrm{sl}}^{2}=\frac{n\left(\lambda_{\mathrm{tr}}\right)^{2}}{3}, \\
n=\frac{3 L_{\mathrm{sl}}^{2}}{\lambda_{\mathrm{tr}}^{2}} \approx \frac{\sum_{\mathrm{tr}}}{\sum_{\mathrm{sl}}}=\frac{\sum_{a}+\sum_{s}(1-(2 / 3 A))}{\sum_{\mathrm{sl}}} .
\end{gathered}
$$

Thus,

$$
n \approx \frac{\sum_{a}+\sum_{s}(1-(2 / 3 A))}{\sum_{s l}} .
$$

According to (11), (14) is obtained as follows:

$$
E_{R}=E_{n} e^{-n \xi}=E_{n} e^{-\left(\left(\sum_{a}+\sum_{s}(1-(2 / 3 A))\right) / \sum_{\mathrm{sl}}\right) \times(2 /(A+(2 / 3)))} .
$$

The variables of $A, E_{n}$, and $\sum_{\mathrm{sl}}$ are as the inputs for Turbo-Pascal programming so that $E_{n}$ is inputted: $12 \mathrm{MeV}$. Therefore according to (14) the values of absorbed dose in the phantom and other components using Turbo-Pascal programming are obtained.

\section{Results}

The derived graphs for absorbed dose in the liver tissue and other components of mentioned system (per emitted neutrons) by both Monte Carlo simulation with nps: $10^{6}$ and analytical method (Turbo-Pascal programming) are as Figures 6, 7, 8, 9, 10, 11, and 12 .

In addition the neutron fluence $\left[\mathrm{n} / \mathrm{cm}^{2}\right]$ or on the other hand the number of neutrons which reach the liver tissue and other components is obtained as Figure 13. Meantime the $X$-axis means the neutron energies reached the phantom's components that are low energies $[\mathrm{eV}]$.

\section{Conclusion}

The absorbed dose by liver tissue in the course of neutron capture therapy has been simulated as function of irradiation time and neutron physical data. This simulation might be

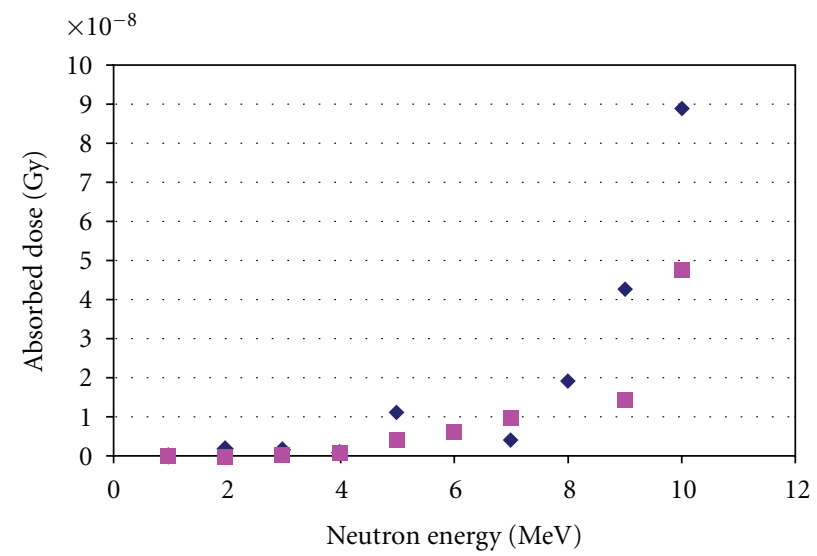

- Absorbed dose (MCNP4C)

- Absorbed dose (Turbo-Pascal)

Figure 6: The absorbed dose in the liver tissue.

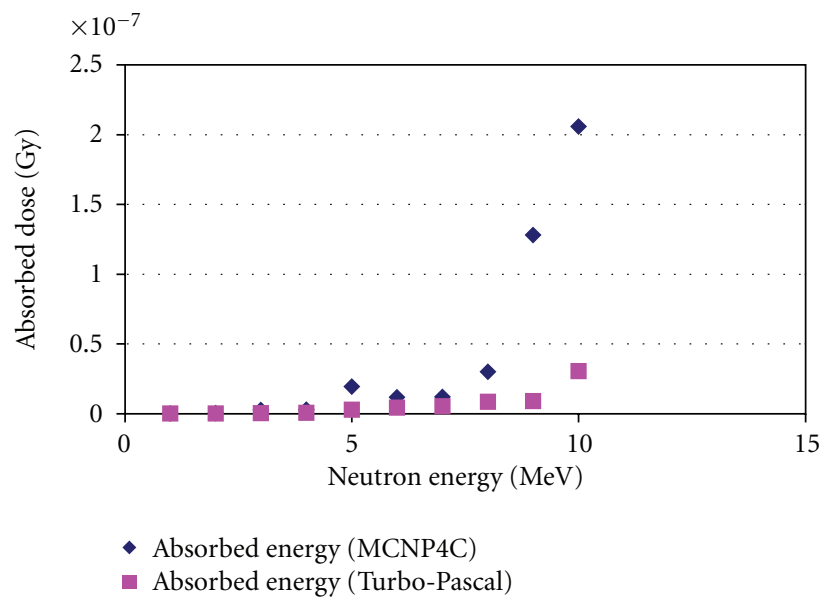

Figure 7: The absorbed dose in the polyethylene sphere.

carried out for various shapes and size of liver, and the results must be saved in a data bank. For each patient, in accord with given required dose for treatment by the clinic and also knowing the specifications of neutron source, the eligible irradiation time according to both the neutron fluence 


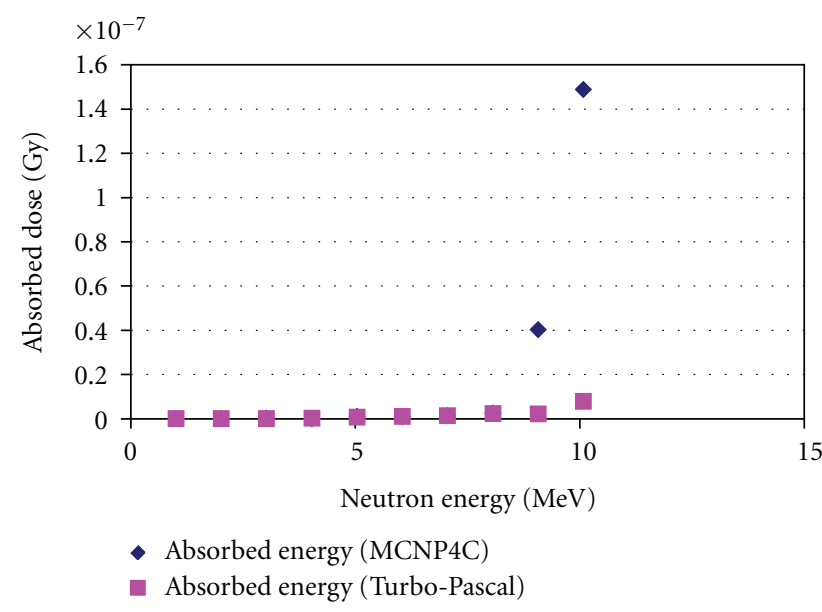

Figure 8: The absorbed dose in the cadmium layer.

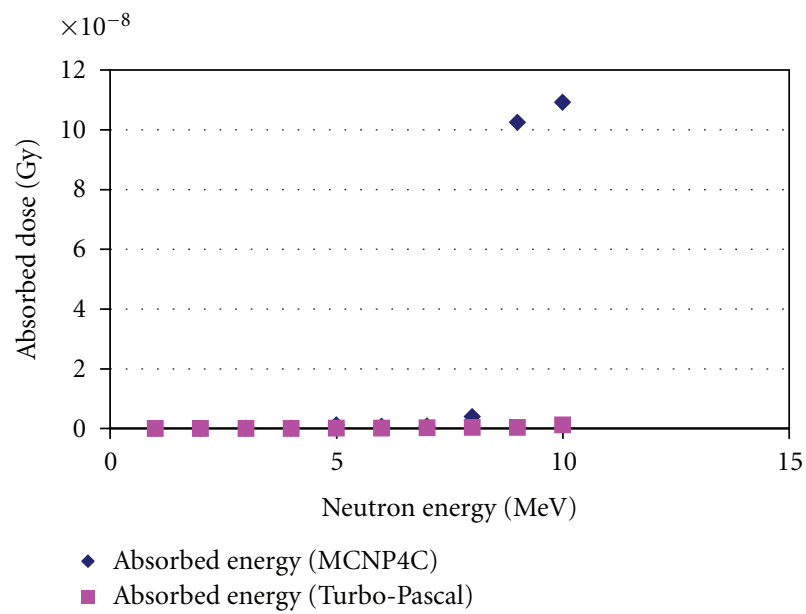

FIgURE 9: The absorbed dose in the air of sphere.

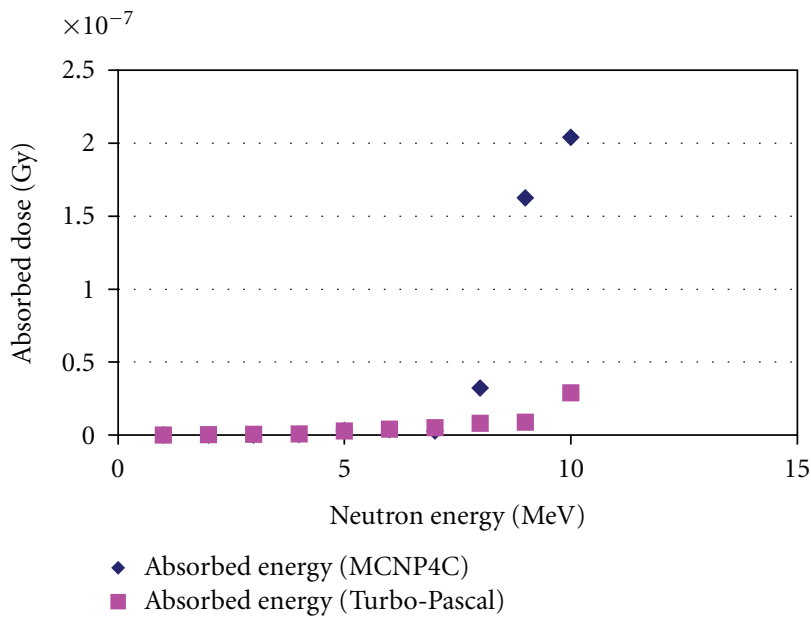

FIgURE 10: The absorbed dose in the collimator.

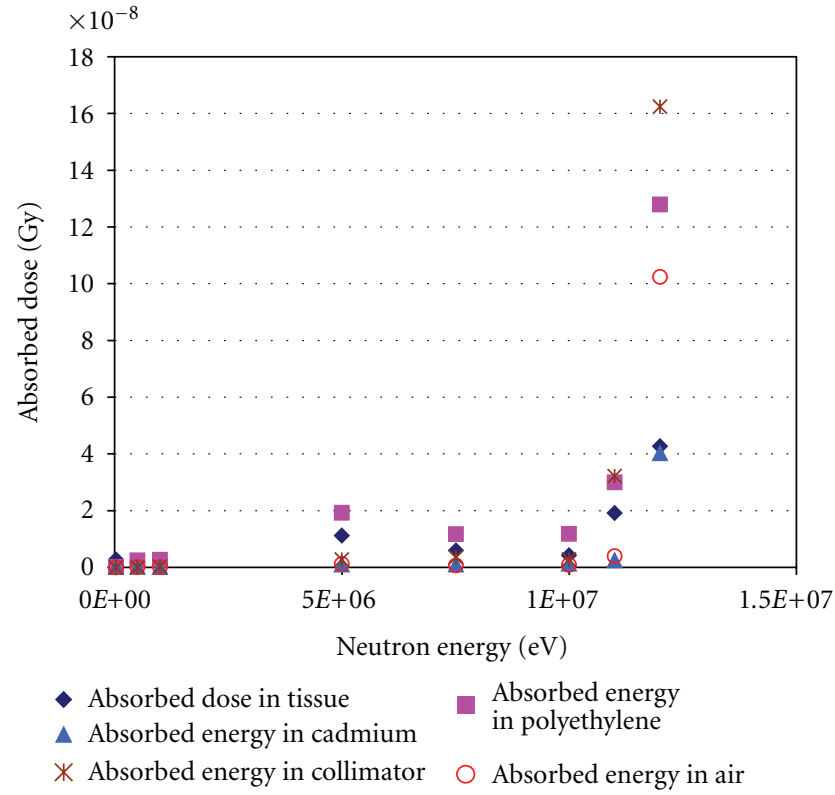

FIgure 11: The absorbed doses in the liver tissue and other components obtained by MCNP4C.

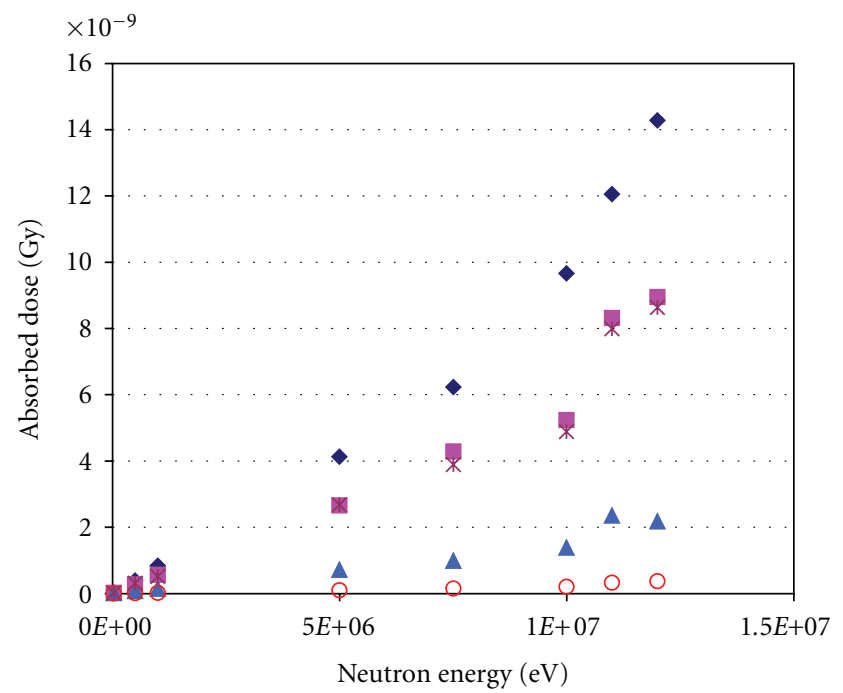
- Absorbed dose in tissue
$\Delta$ Absorbed energy in cadmium
Absorbed energy in polyethylene
* Absorbed energy in collimator
$\bigcirc$ Absorbed energy in air

FIGURE 12: The absorbed doses in the liver tissue and other components obtained by Turbo-Pascal programming.

and energy of existing clinical neutron source through the present simulation is obtained. Meantime the neutron energy reached the eligible interval of energy on the tissue computed by (14).

Therefore in case there is no eligible clinical neutron source for NCT, then this model of phantom might be utilized to reach the desirable energy range of neutrons according to the required energy in NCT. 


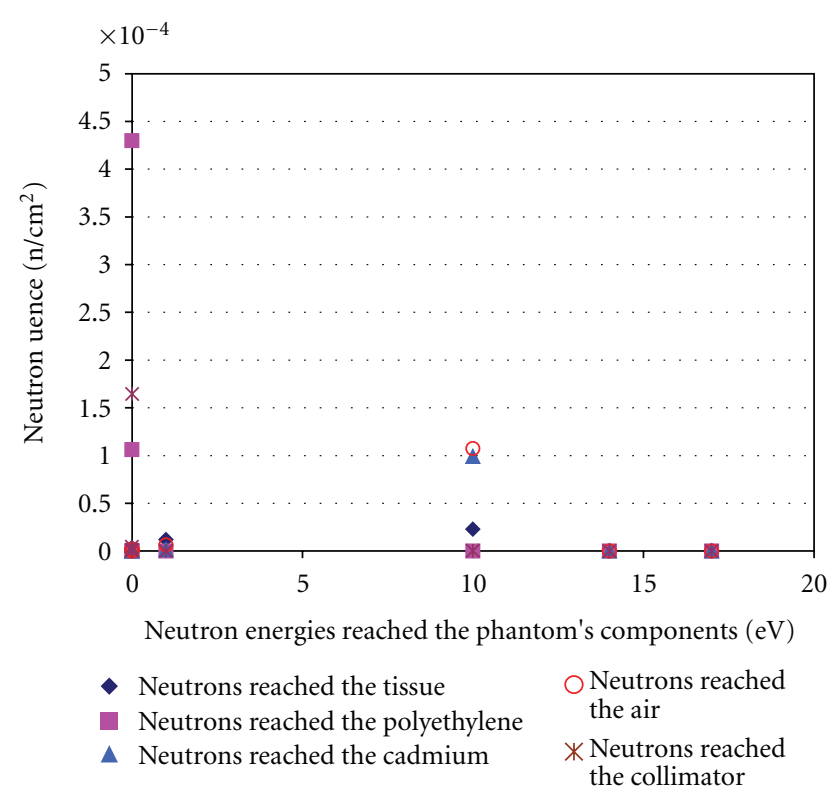

FIgURE 13: The neutron fluence in the phantom's components obtained by MCNP4C.

From Figures 6-10 it is observed that within neutron energy range of $0.001 \mathrm{eV}-8 \mathrm{MeV}$ the computed dose by Turbo-Pascal programming is approximately similar to obtained results by MCNP code, and the derived graphs of both methods agree together as well for neutron energy below $8 \mathrm{MeV}$. Actually, through increasing incident neutron energy, the absorbed dose is increased. For neutron energy above $8 \mathrm{MeV}$, the results of these two approaches produce significant error. This is because of computation based on MCNP code that computation bases of this code are transport equation and neutron tracking. The equations in TurboPascal programming include diffusion approximations. In addition for neutron energy greater than $8 \mathrm{MeV},(n, \alpha)$ reactions become more probable to occur. In such nonelastic reactions, the angular distribution of incident neutron and the recoiled nucleus are complicated more than lower energies. This is observed in Figure 7 for polyethylene as well. The absorbed dose in polyethylene phantom is increased through neutron energy so that excess doses may be delivered to the liver tissue. Meantime the absorbed doses because of thermal and epithermal neutron irradiation are negligible.

\section{Nomenclature}

$\begin{array}{ll}P_{1}, P_{2}, P_{3}, P_{4}, P_{5}: & \text { Probability of events } \\ E_{1}: & \text { Initial energy of neutron } \\ E_{2}: & \text { Final energy of neutron after } \\ & \text { interaction } \\ & \text { The angle between the course of } \\ & \text { projectile neutron and recoiled } \\ & \text { nucleus in the laboratory system } \\ n: & \text { The number of collisions to reach the } \\ & \text { eligible energy }\end{array}$

A: Mass number of the components of the phantom

$E_{n}$ : Energy of incident neutron

$\overline{E_{R}}$ : Deposited energy

$E_{R}$ : The energy of thermal neutrons which have reached the eligible energy

$\xi: \quad$ Lethargy

$L_{\mathrm{sl}}$ : Slowing down length

$\lambda_{\mathrm{tr}}$ : Mean free distance of transport

$\Sigma_{\mathrm{tr}}$ : Macroscopic transport cross-section

$\Sigma_{\mathrm{sl}}$ : Macroscopic slowing down cross section

$\Sigma_{a}$ : Macroscopic absorption cross section

$\Sigma_{s}$ : Macroscopic scattering cross section

$\Sigma_{\text {tot }}$ : Macroscopic total cross section

$\Sigma_{C}$ : Macroscopic absorption cross section for carbon

$\Sigma_{H}$ : Macroscopic absorption cross section for hydrogen.

\section{Acknowledgment}

This paper is related to a research project entitled: "Design and Theoretical Simulation of a New System for Neutron Capture Therapy (NCT) of a Sample Tissue for Determination of Requirement Duration and Determination of Absorbed Dose and Preparing the Favorite Energy of Clinical Source" that by sponsorship and financial supporting the "Islamic Azad University-South Tehran Branch" has been carried out.

\section{References}

[1] E. C. C. Pozzi, S. Thorp, J. Brockman, M. Miller, D. W. Nigg, and M. Frederick Hawthorne, "Intercalibration of physical neutron dosimetry for the RA-3 and MURR thermal neutron sources for BNCT small-animal research," Applied Radiation and Isotopes, vol. 69, no. 12, pp. 1921-1923, 2011.

[2] R. L. Moss, O. Aizawa, D. Beynon et al., "The requirements and development of neutron beams for neutron capture therapy of brain cancer," Journal of Neuro-Oncology, vol. 33, no. 1-2, pp. 27-40, 1997.

[3] M. Reginatto, "What can we learn about the spectrum of high-energy stray neutron fields from Bonner sphere measurements?" Radiation Measurements, vol. 44, no. 7-8, pp. 692699, 2009.

[4] M. L. Andrieux, B. Dinkespiler, J. Lundquist, O. Martin, and M. Pearce, "Neutron and gamma irradiation studies of packaged VCSEL emitters for the optical read-out of the ATLAS electromagnetic calorimeter," Nuclear Instruments and Methods in Physics Research, vol. 426, no. 2, pp. 332-338, 1999.

[5] M. P. Dhairyawan, P. S. Nagarajan, and G. Venkataraman, "Response functions of spherically moderated neutron detectors," Nuclear Instruments and Methods, vol. 169, no. 1, pp. 115-120, 1980.

[6] A. Bolewski, M. Ciechanowski, A. Dydejczyk, and A. Kreft, "On the optimization of the isotopic neutron source method for measuring the thermal neutron absorption cross section: advantages and disadvantages of BF3 and $3 \mathrm{He}$ counters," Applied Radiation and Isotopes, vol. 66, no. 4, pp. 457-462, 2008. 
[7] H. R. Vega-Carrillo, V. Hernandez-Davila, E. ManzanaresAcuña et al., "Neutron spectrometry using artificial neural networks," Radiation Measurements, vol. 41, no. 4, pp. 425431, 2006.

[8] F. Trompier, P. Battaglini, D. Tikunov, and I. Clairand, "Dosimetric response of human bone tissue to photons and fission neutrons," Radiation Measurements, vol. 43, no. 2-6, pp. 837840, 2008.

[9] G. Bartesaghi, J. Burian, G. Gambarini, M. Marek, A. Negri, and L. Viererbl, "Evaluation of all dose components in the LVR-15 reactor epithermal neutron beam using Fricke gel dosimeter layers," Applied Radiation and Isotopes, vol. 67, no. 7-8, pp. S199-S201, 2009.

[10] D. Zhou, E. Semones, R. Gaza et al., "Radiation measured during ISS-Expedition 13 with different dosimeters," Advances in Space Research, vol. 43, no. 8, pp. 1212-1219, 2009.

[11] S. J. González, M. R. Bonomi, G. A. S. Santa Cruz et al., "First BNCT treatment of a skin melanoma in Argentina: dosimetric analysis and clinical outcome," Applied Radiation and Isotopes, vol. 61, no. 5, pp. 1101-1105, 2004.

[12] J. McBride, M. Mason, and E. Scott, "The storage of the major liver components," The Journal of Biological Chemistry, vol. 1, pp. 943-952, 1941.

[13] J. T. Goorley, W. S. Kiger, and R. G. Zamenhof, "Reference dosimetry calculations for Neutron Capture Therapy with comparison of analytical and voxel models," Medical Physics, vol. 29, no. 2, pp. 145-156, 2002.

[14] T. Tagami and S. Nishimura, "Intercalibration of thermal neutron dosimeter glasses NBS-SRM612 and corning 1 in some irradiation facilities: a comparison," International Journal of Radiation Applications and Instrumentation. Part, vol. 16, no. 1, pp. 11-14, 1989.

[15] D. Rochman, R. C. Haight, S. A. Wender et al., "First measurements with a lead slowing-down spectrometer at LANSCE," in Proceedings of the International Conference on Nuclear Data for Science and Technology (AIP '04), pp. 736-739, October 2004.

[16] T. Matsumoto, H. Harano, Y. Ito, A. Uritani, K. Emi, and K. Kudo, "Development of a fast neutron spectrometer composed of silicon-SSD and position-sensitive proportional counters," Radiation Protection Dosimetry, vol. 110, no. 1-4, pp. 223-226, 2004.

[17] J. Chuncheng, G. H. R. Kegel, J. J. Egan et al., "Measurement of U-235 fission neutron spectra using a multiple gamma coincidence technique," in Proceedings of the International Conference on Nuclear Data for Science and Technology (AIP '04), vol. 769, pp. 1051-1053, October 2004.

[18] H. Kahn, "Application of Monte Carlo," USAEC Report AECU-3259, Rand Corporation, Santa Monica, Calif, USA, 1954.

[19] S. Y. Hohara, M. Imamura, T. Kin et al., "Development of gas proportional scintillation counter for light heavy-ion detection," in Proceedings of the International Conference on Nuclear Data for Science and Technology (AIP '04), pp. 773-775, October 2004.

[20] S. H. Shinde and T. Mukherjee, "Sensitization of glycine (spectrophotometric read-out) dosimetric system using sorbitol," Radiation Measurements, vol. 44, no. 4, pp. 378-383, 2009.

[21] T. Taosheng, L. Dong, and H. Li, "A Monte Carlo design of a neutron dose-equivalent survey meter based on a set of $3 \mathrm{He}$ proportional counters," Radiation Measurements, vol. 42, no. 1, pp. 49-54, 2007.

[22] M. Stacy, Nuclear Reactor Physics (SE), Chapter 5, John Wiley Publishing Company, New York, NY, USA, 2007. 

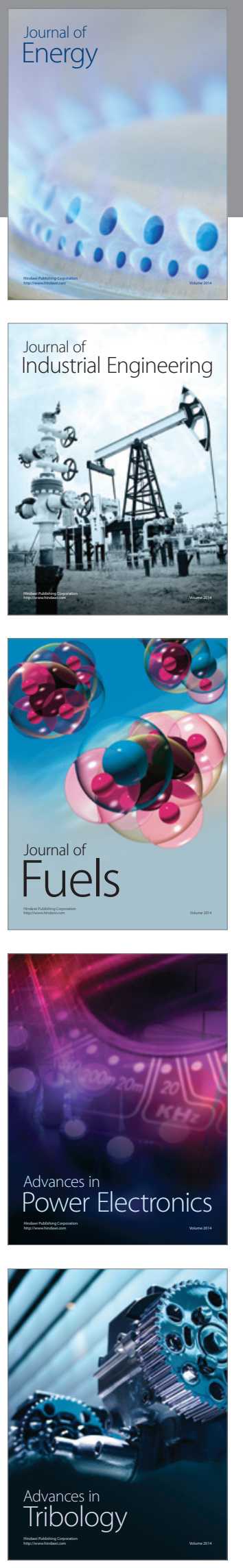
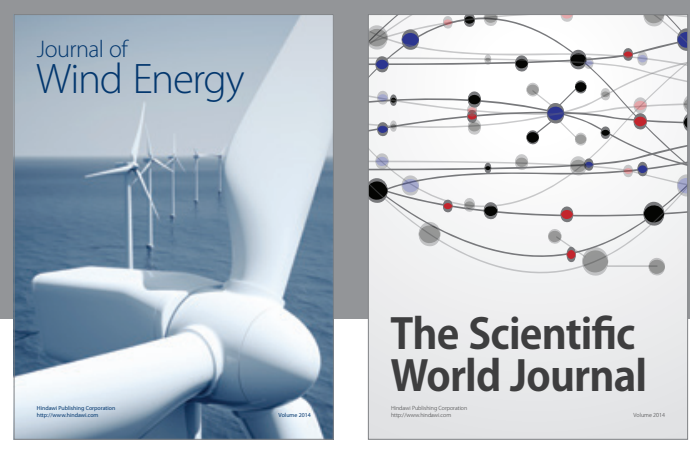

The Scientific World Journal

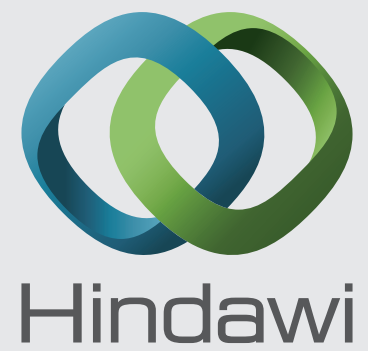

Submit your manuscripts at http://www.hindawi.com
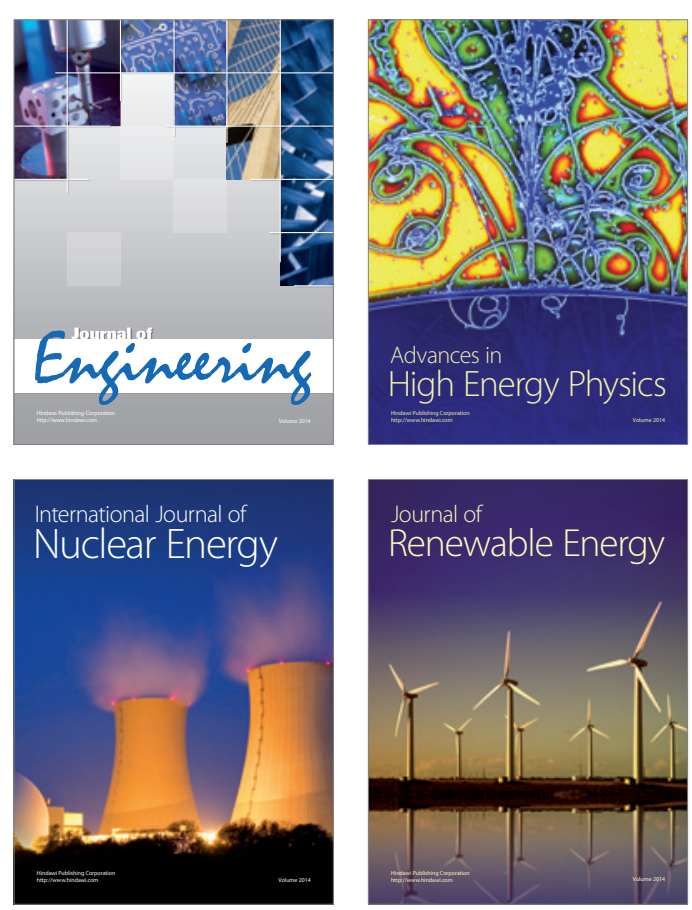

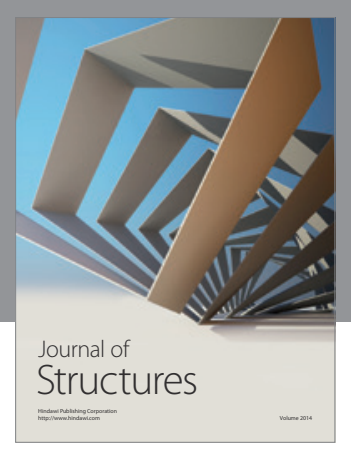

Rotating
Mechinery
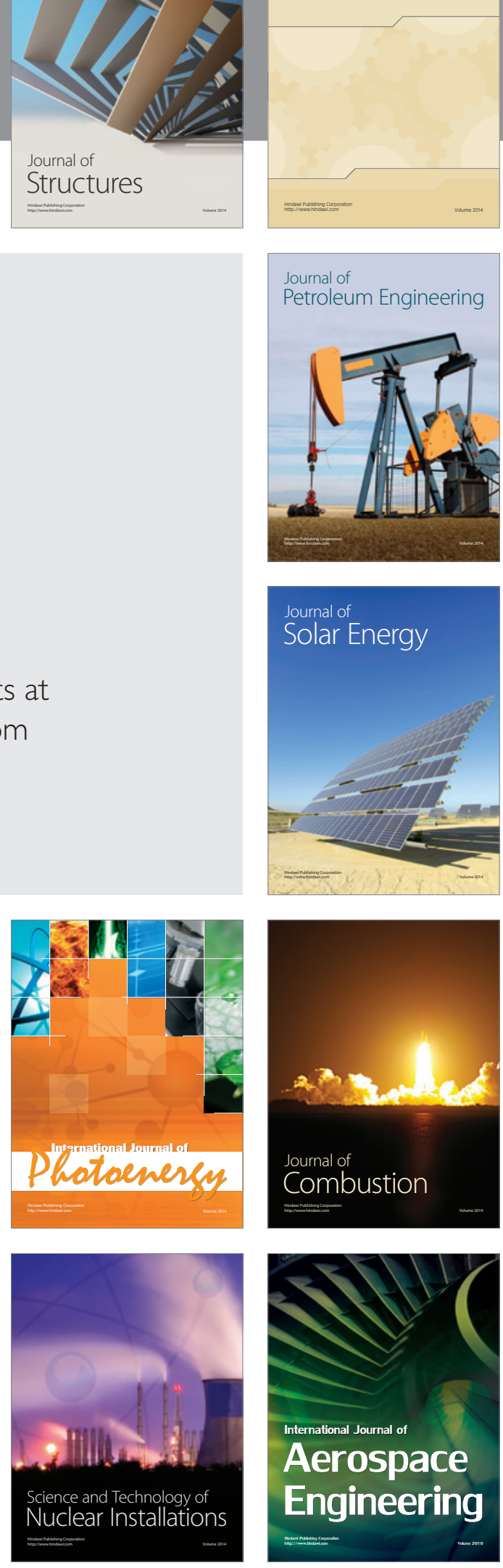